\title{
Gamma Attenuation Behavior of Some Stainless and Boron Steels
}

\author{
B. BUYUK* \\ Istanbul Technical University, Energy Institute, Nuclear Researches Division, \\ Ayazaga Campus, 34469, Sariyer, Istanbul, Turkey
}

\begin{abstract}
In the present work gamma attenuation behavior of some commonly used commercial stainless steels and boron steels were investigated. 303, 304, 310, 316, 430 stainless steels and ZF7B, 27M12C5B, 30MNB5 boron steels were studied against Cs-137 and Co-60 gamma radioisotopes. The linear and mass attenuation coefficients of the samples were measured by using gamma transmission technique. Mass attenuation coefficients were compared with the theoretical values which were calculated by using XCOM computer code. Theoretical and experimental mass attenuations were closed to each other. In addition half-value thickness (HVT) values of the samples were calculated and compared with the results of lead $(\mathrm{Pb})$. European Union has published the directive in 2002 and recast in 2011 about Restriction of Some Hazardous Substances (RoHS) which included Pb. This study shows that 303, 304, 310 and 316 stainless steels and ZF7B, 27M12C5B, 30MNB5 boron steels are some of the candidate materials for using in gamma shielding applications instead of lead.
\end{abstract}

DOI: $10.12693 /$ APhysPolA.127.1342

PACS: 25.20Dc

\section{Introduction}

European Union has released a directive in 2002 and recast in 2011 about restriction of the use of some hazardous substances (RoHS) which includes lead $(\mathrm{Pb})$ in electrical and electronic equipment [1]. It has been also reported that there is no economic substitution material for the lead in these devices and systems [2]. It is known that lead is a commonly used radiation shielding material in nuclear applications and devices, because of its good shielding properties and low cost. On the other hand the lead is a toxic material, thus there are some studies intended to find alternative materials, which could be used in radiation shielding applications instead of the lead. Steels, tungsten alloys, concrete, aluminum alloys are some of these candidate material [3-5].

In this study 303, 304, 310, 316, 430 stainless steels (SSs) and ZF7B, 27M12C5B, 30MNB5 boron steels (BSs) were investigated against gamma radiation sources (Cs-137 and Co-60). The study of gamma attenuation properties was carried out and results are compared with the properties of lead and other candidate materials. The possible uses of the steels instead of lead in radiation shielding applications were evaluated by the view of RoHS Directive.

\section{Experimental procedure}

Gama transmission technique, a schematic view of which is given in Fig. 1, is based on penetration of gamma rays through materials. The gamma rays which come from the source are detected with/without material [6].

\footnotetext{
*e-mail: buyukbu@itu.edu.tr
}

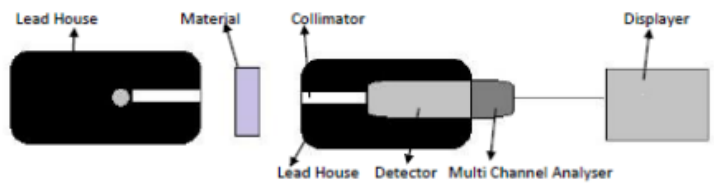

Fig. 1. The schematic view of the gamma transmission measurement technique.

In the experiments $\mathrm{Cs}-137$ and $\mathrm{Co}-60$ gamma sources were used, which have activities of $8.5 \mu \mathrm{Ci}$ and $8.32 \mu \mathrm{Ci}$, respectively. Cs-137 has one gamma peak at energy of $0.662 \mathrm{MeV}$ and half life of 30.1 years [7]. Co-60 has two gamma peaks at 1.17 and $1.33 \mathrm{MeV}(1.25 \mathrm{MeV}$ mean) [7]. The half life of Co-60 is 5.27 years. Canberra Model (8022X2) NaI Scintillation detector was placed $14 \mathrm{~cm}$ from the source. Both the detector and source were put in the lead houses ( $5 \mathrm{~cm}$ thick), which have a $7 \mathrm{~mm}$ hole on the same axis, to see each other and minimize the scattering effect. The accumulation time was adjusted to 300 seconds. Afterwards source was placed and initial gamma radiation $I_{0}$ was measured. Finally, for each material, the gamma counts $I$ were detected at different material thicknesses. To get rational evaluation, relative counts $I / I_{0}$ were calculated for different thickness values of the samples and evaluated.

303, 304, 310, 316 and 430 type stainless steels and ZF7B, 27M12C5B, 30MNB5 boron steels were used in the experiments. The contents of the studied steels is given in Table I.

\section{Results and discussion}

The relative counts at different thickness values of the samples were measured and the results are given in the Table II. In the experiments the graphs in Fig. 2 were fitted according to Beer Lambert's law which is 
Contents (\%) and density $\rho\left(\mathrm{g} / \mathrm{cm}^{3}\right)$ of the studied stainless steels and the boron steels

TABLE I [8-10]. *27M12C5B

\begin{tabular}{|c|c|c|c|c|c|c|c|c|}
\hline & 303 & 304 & 310 & 316 & 430 & ZF7B & $27 \mathrm{M}^{*}$ & $30 \mathrm{MNB} 5$ \\
\hline $\mathrm{Cr}$ & $17-19$ & $18-20$ & $24-26$ & $16-18$ & $16-18$ & 1.25 & 0.5 & 0.1 \\
\hline $\mathrm{Ni}$ & $8-10$ & $8-10.50$ & $19-22$ & $10-14$ & 0.75 & 0.17 & 0.06 & 0.06 \\
\hline $\mathrm{C}$ & 0.15 & 0.08 & 0.25 & 0.08 & 0.12 & 0.17 & 0.29 & 0.31 \\
\hline $\mathrm{Mn}$ & 2 & 2 & 2 & 2 & 1 & 1.21 & 1.25 & 1.25 \\
\hline $\mathrm{Si}$ & 1 & 0.75 & 1.5 & 0.75 & 1 & 0.24 & 0.23 & 0.22 \\
\hline $\mathrm{P}$ & 0.2 & 0.045 & 0.045 & 0.045 & 0.04 & 0.16 & 0.01 & 0.014 \\
\hline $\mathrm{S}$ & $0.15 \mathrm{~min}$ & 0.03 & 0.03 & 0.03 & 0.03 & 0.03 & 0.003 & 0.008 \\
\hline $\mathrm{N}$ & - & 0.1 & - & 0.1 & - & 0.0132 & 0.0065 & 0.0071 \\
\hline Mo & 0.6 & - & - & $2.0-3.0$ & - & 0.07 & 0.02 & 0.02 \\
\hline $\mathrm{Al}$ & - & - & - & - & - & 0.03 & 0.024 & 0.011 \\
\hline $\mathrm{Cu}$ & - & - & - & - & - & 0.18 & 0.15 & 0.16 \\
\hline $\mathrm{Sn}$ & - & - & - & - & - & 0.014 & 0.009 & 0.016 \\
\hline B & - & - & - & - & - & 0.0024 & 0.0021 & 0.0019 \\
\hline $\mathrm{Ti}$ & - & - & - & - & - & 0.002 & 0.043 & 0.035 \\
\hline $\mathrm{Fe}$ & \multicolumn{8}{|c|}{ Balance } \\
\hline$\rho$ & 8.00 & 8.03 & 8.00 & 7.99 & 7.74 & 7.85 & 7.85 & 7.85 \\
\hline
\end{tabular}

given below $[6]$

$$
I=I_{0} e^{-\mu x},
$$

where $I$ and $I_{0}$ are gamma ray intensity with and without material, respectively and $\mu$ is the linear attenuation coefficient for the sample at specific gamma ray energy and $x$ is the material thickness.

The 304 SS has the highest gamma attenuation capability for either Cs-137 (Fig. 2a) or Co-60 (Fig. 2b) gamma sources. On the other hand, for boron steels 30MNB5 has the highest gamma reduction ability for Cs-137 gamma source (Fig. 2c) and 27M12C5B has the highest Co-60 gamma attenuation (Fig. 2d) capability. The linear attenuation coefficients for the studied steels were determined according to Eq. 1 and the results are presented in Table III.

The Cs-137 linear attenuation coefficients of the stainless steels were higher than those of boron steels, with the exception of 430 steel. However it was hard to make same generalization for Co-60 linear attenuations coefficients. The 304 stainless steel had the biggest linear attenuation coefficient for both Cs-137 and Co-60 gamma radioisotopes. From the experimental results, the mass attenuation coefficients $\mu / \rho$ of the samples were calculated. On the other hand the theoretical mass attenuation coefficients of the samples were determined using $\mathrm{XCOM}$ computer code which is a commonly used code in the literature [11]. The experimental and theoretical mass attenuations and differences expressed in percents are presented in Table IV.

It can be seen from the Table IV, that the theoretical (XCOM) mass attenuation coefficients are close to experimental ones with the average difference of $3.24 \%$, which is caused by the impurities in the samples and by the production methods.

Half-value thicknesses (HVTs), which mean the material thickness needed to reduce the incoming gamma ray
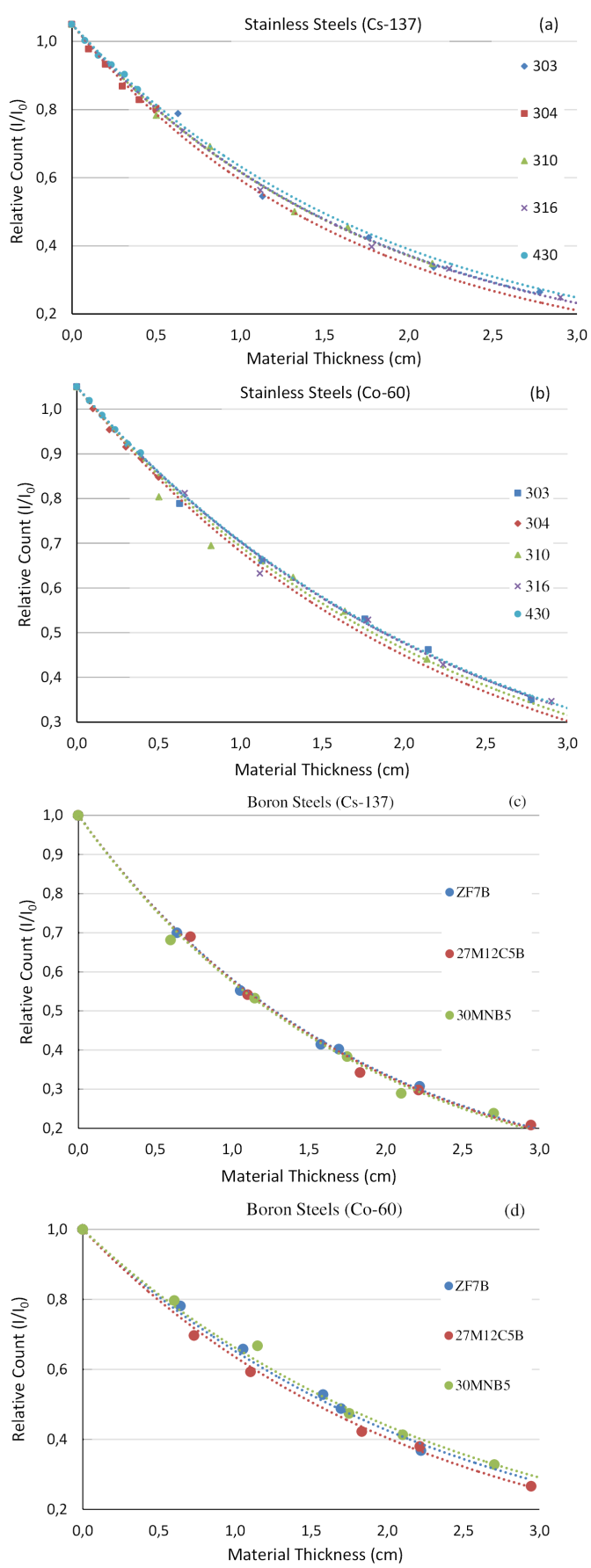

Fig. 2. Relative counts number as function of material thickness for the stainless steels shielding Cs-137 (a) and Co-60 (b) gamma sources and for boron steels shielding Cs-137 (c) and Co-60 (d) gamma sources.

intensity to its half value, were calculated and are given in Table $\mathrm{V}$.

The stainless steels have smaller HVT values than the boron steels (with exception of 430). On the other hand, all of them have bigger HVT values than $\mathrm{Pb}$ and $\mathrm{W}$ for both $\mathrm{Cs}-137$ and $\mathrm{Co}-60$. 304 SS was the closest material to lead and tungsten, considering the gamma attenuation properties. It means that stainless steels have infe- 
Relative counts values for differ- TABLE II ent thicknesses of the stainless and boron steels.

\begin{tabular}{|c|c|c|c|}
\hline Material & Thickness & $\begin{array}{c}\text { Cs-137 } \\
\text { Rel. Count }\end{array}$ & $\begin{array}{c}\text { Co-60 } \\
\text { Rel. Count }\end{array}$ \\
\hline$I_{0}$ & 0 & 1 & 1 \\
\hline \multirow{5}{*}{303} & 0.6303 & 0.7376 & 0.7386 \\
\hline & 1.1335 & 0.4951 & 0.6110 \\
\hline & 1.7638 & 0.3741 & 0.4800 \\
\hline & 2.1498 & 0.2869 & 0.4117 \\
\hline & 2.7801 & 0.2140 & 0.2996 \\
\hline \multirow{5}{*}{304} & 0.1000 & 0.9274 & 0.9509 \\
\hline & 0.2000 & 0.8822 & 0.9041 \\
\hline & 0.3000 & 0.8180 & 0.8650 \\
\hline & 0.4000 & 0.7781 & 0.8379 \\
\hline & 0.5000 & 0.7528 & 0.7977 \\
\hline \multirow{5}{*}{310} & 0.5025 & 0.7330 & 0.7539 \\
\hline & 0.8210 & 0.6410 & 0.6444 \\
\hline & 1.3235 & 0.4495 & 0.5737 \\
\hline & 1.6397 & 0.4042 & 0.4976 \\
\hline & 2.1422 & 0.2974 & 0.3906 \\
\hline \multirow{5}{*}{316} & 0.6611 & 0.6880 & 0.7622 \\
\hline & 1.1202 & 0.5133 & 0.5826 \\
\hline & 1.7813 & 0.3468 & 0.4788 \\
\hline & 2.2417 & 0.2826 & 0.3783 \\
\hline & 2.9028 & 0.1986 & 0.2966 \\
\hline \multirow{5}{*}{430} & 0.0782 & 0.9523 & 0.9688 \\
\hline & 0.1564 & 0.9087 & 0.9361 \\
\hline & 0.2346 & 0.8812 & 0.9038 \\
\hline & 0.3128 & 0.8530 & 0.8715 \\
\hline & 0.3910 & 0.8082 & 0.8519 \\
\hline \multirow{5}{*}{ ZF7B } & 0.6426 & 0.6994 & 0.7809 \\
\hline & 1.0538 & 0.5521 & 0.6577 \\
\hline & 1.5788 & 0.4142 & 0.5276 \\
\hline & 1.6964 & 0.4019 & 0.4881 \\
\hline & 2.2214 & 0.3068 & 0.3676 \\
\hline \multirow{5}{*}{$27 \mathrm{M} 12 \mathrm{C} 5 \mathrm{~B}$} & 0.7314 & 0.6892 & 0.6969 \\
\hline & 1.1024 & 0.5415 & 0.5929 \\
\hline & 1.8338 & 0.3425 & 0.4222 \\
\hline & 2.2148 & 0.2974 & 0.3795 \\
\hline & 2.9462 & 0.2083 & 0.2656 \\
\hline \multirow{5}{*}{ 30MNB5 } & 0.6014 & 0.6812 & 0.7967 \\
\hline & 1.1484 & 0.5322 & 0.6674 \\
\hline & 1.7498 & 0.3829 & 0.4739 \\
\hline & 2.1025 & 0.2891 & 0.4130 \\
\hline & 2.7039 & 0.2384 & 0.3279 \\
\hline
\end{tabular}

rior gamma attenuation properties than lead and tungsten. However the stainless and boron steels have higher gamma attenuation capability than concrete and aluminum alloys [3-5]. Even though tungsten is an alternative material for lead in nuclear applications, the price of tungsten restricts its usage. On the other hand 304 SS has acceptable commercial price, to be use it in nuclear applications instead of lead.
TABLE III

The linear attenuation coefficients $\left(\mathrm{cm}^{-1}\right)$ of the stainless and boron steels for Cs-137 and Co-60 sources.

\begin{tabular}{c|c|c|c|c}
\hline \hline Material & $\begin{array}{c}\text { Cs-137 } \\
(0.662 \mathrm{MeV})\end{array}$ & $\begin{array}{c}\text { Std. } \\
\text { Dev. }\end{array}$ & $\begin{array}{c}\text { Co-60 } \\
(1.25 \mathrm{MeV})\end{array}$ & $\begin{array}{c}\text { Std. } \\
\text { Dev. }\end{array}$ \\
\hline 303 & 0.565 & 0.017 & 0.426 & 0.008 \\
304 & 0.609 & 0.032 & 0.459 & 0.009 \\
310 & 0.569 & 0.017 & 0.442 & 0.021 \\
316 & 0.568 & 0.007 & 0.426 & 0.011 \\
430 & 0.539 & 0.013 & 0.423 & 0.006 \\
ZF7B & 0.543 & 0.005 & 0.427 & 0.009 \\
27 M12C5B & 0.547 & 0.010 & 0.453 & 0.008 \\
30MNB5 & 0.554 & 0.014 & 0.412 & 0.012
\end{tabular}

The mass attenuation coefficients $\mu_{m}\left(\mathrm{~cm}^{2} / \mathrm{g}\right)$ of the stainless and boron steels for Cs-137 and Co-60 sources.

\begin{tabular}{c|c|c|c}
\hline \hline Material & Experimental & $\begin{array}{c}\text { Theoretical } \\
(\text { XCOM })\end{array}$ & $\begin{array}{c}\text { Difference } \\
(\%)\end{array}$ \\
\hline \multicolumn{3}{c}{ Cs-137 } \\
\hline 303 & 7.063 & 7.252 & 2.61 \\
304 & 7.584 & 7.252 & 4.58 \\
310 & 7.113 & 7.271 & 2.18 \\
316 & 7.109 & 7.252 & 1.97 \\
430 & 6.964 & 7.238 & 3.79 \\
ZF7B & 6.917 & 7.246 & 4.54 \\
27M12C5B & 6.968 & 7.246 & 3.83 \\
30 MNB5 & 7.057 & 7.246 & 2.60 \\
\hline \multicolumn{3}{|c}{ Co-60 } \\
\hline 303 & 5.325 & 5.327 & 0.04 \\
304 & 5.716 & 5.327 & 7.30 \\
310 & 5.525 & 5.34 & 3.46 \\
316 & 5.332 & 5.327 & 0.09 \\
430 & 5.465 & 5.317 & 2.79 \\
ZF7B & 5.439 & 5.322 & 2.21 \\
27M12C5B & 5.771 & 5.322 & 8.43 \\
$30 M N B 5$ & 5.248 & 5.322 & 1.38 \\
\end{tabular}

TABLE V

The half-value thicknesses HVT $(\mathrm{cm}),(0.693 / \mu)$, of the stainless and boron steels and lead for Cs-137 and Co-60 sources.

\begin{tabular}{c|c|c|}
\hline \hline Material & Cs-137 & Co-60 \\
\hline 303 & 1.227 & 1.627 \\
304 & 1.138 & 1.510 \\
310 & 1.218 & 1.568 \\
316 & 1.220 & 1.627 \\
430 & 1.286 & 1.639 \\
ZF7B & 1.277 & 1.623 \\
27M12C5B & 1.267 & 1.530 \\
30MNB5 & 1.251 & 1.682 \\
Lead (Pb) [3] & 0.660 & 1.109 \\
Tungsten [3] & 0.407 & 0.676 \\
Concrete [5] & 4.8 & 6.6 \\
Aluminum [5] & 3.37 & 4.61
\end{tabular}




\section{Conclusions}

303, 304, 310, 316 and 430 stainless steels and ZF7B, 27M12C5B, 30MNB5 boron steels were investigated against Cs-137 and Co-60 gamma radioisotope sources. The measurements of gamma attenuation properties of the steels were carried out. The experimental mass attenuations were close to theoretical ones, with the average difference of $3.24 \%$, which is the result of impurities and production method. In addition HVT values for each sample were calculated and interpreted to another and compared to lead. Although the steels have less HVTs and larger production cost than lead, they have lower production cost than tungsten and tungsten alloys. Therefore, stainless steels and boron steels are still promising candidate materials in gamma shielding applications instead of lead.

\section{Acknowledgments}

The author thanks to Prof. Dr. A. Beril TUGRUL, Mehmet CAKICI and ASIL CELIK Company for their useful support.

\section{References}

[1] DIRECTIVE $2011 / 65 / \mathrm{EU}$ on the restriction of the use of certain hazardous substances in electrical and electronic equipment (recast), http://eur-lex.europa.eu/legal-content/en/ TXT/?uri=celex:32011L0065, Official Journal of the European Union 1.7.2011 L 174, 88 (2011).
[2] R. Groß, D. Bunke, C.-O. Gensch, S. Zangl, A. Manhart, http://ec.europa.eu/environment/waste/ weee/pdf/hazardous_substances_report.pdf, Study on Hazardous Substances in Electrical and Electronic Equipment, Not Regulated by the RoHS Directive, 2008.

[3] B. Buyuk, A.B. Tugrul, Acta Physica Polonica A 125, 423 (2014).

[4] H. Durmaz, A.B. Tugrul, B. Buyuk, Acta Physica Polonica A 125, 469 (2014).

[5] L. Mordfin, http://www.astm.org/DIGITAL_ LIBRARY/MNL/SOURCE_PAGES/DS68.htm Handbook of reference data for non-destructive testing, ASTM Data series, DS68, USA, 2002.

[6] B. Buyuk, A.B. Tugrul, Radiation Physics and Chemistry 97, 354 (2014).

[7] B. Buyuk, A.B. Tugrul, Annals of Nuclear Energy 71, 46 (2014).

[8] http://asm.matweb.com/search/ SpecificMaterial.asp?bassnum=MQ303H, accessed 15.03.2014.

[9] http://www.azom.com/article.aspx?ArticleID= 4392, accessed 15.03.2014.

[10] http://www.gkn.com/hoeganaes/ technologyandinnovation/ Technical-Library-by-Topic/stainless-steel/ Pages/boron-steels.aspx, accessed 15.03.2014.

[11] M.J. Berger, J.H. Hubbell, S.M. Seltzer, J. Chang, J.S. Coursey, R. Sukumar, D.S. Zucker, K. Olsen, http://www.nist.gov/pml/data/xcom/, XCOM: photon crossection database, USA, 2014. 